\title{
Rapid and Sensitive Analysis of mRNA Polyadenylation States by PCR
}

\author{
Fernando J. Sallés ${ }^{1}$ and Sidney Strickland
}

Department of Pharmacology, University Medical Center at Stony Brook, Stony Brook, New York 11794-8651

\begin{abstract}
A rapid and sensitive technique is described that measures the length of the poly(A) tail on a specific mRNA within subnanogram quantities of total cellular RNA [the Poly(A) test (PAT)]. In a single-tube reaction, a poly(dT) primer is synthesized in situ on the poly(A) tail of mRNAs using oligo(dT) and DNA ligase. By modulating the annealing temperature and primer concentrations, a CC-rich adapter sequence is targeted to the $5^{\prime}$ end of the poly(dT) primer. This ligated poly(dT)-anchor is then used to prime reverse transcription of the $m R N A$, yielding a library of PAT cDNAs. The length of a poly(A) tail is determined by PCR amplification using the oligo(dT)-anchor primer and a message-specific primer. Comparison of PCR products from different samples allows quantitative determination of changes in polyadenylation of a given mRNA. This technique overcomes many of the pitfalls associated with conventional poly(A) tail length assessments and should prove useful in studying a variety of processes relating to polyadenylation.
\end{abstract}

'Present address: The Picower Institute for Medical Research, Manhasset, New York 11030. he length of the polyadenylate [poly(A)] tail on mRNAs has emerged as an important regulatory element. Previous assays for polyadenylation have relied on Northern analysis of mRNAs following oligo(dT) hybridization and RNase H cleavage (e.g., see Ref. 1). Comparison of RNA samples in the presence and absence of RNase $\mathrm{H}$ allows analysis of differential polyadenylation states. This procedure has several drawbacks: (1) Because the RNA is detected by Northern analysis and several controls are required for each mRNA, a relatively large initial sample size is needed; (2) precise quantitation of $\operatorname{poly}(\mathrm{A})$ tail length is difficult because of the limits of conventional agarose gel electrophoresis used in Northern analysis; (3) extended adenosine residue stretches within the RNA could complicate the analysis of polyadenylation because they too can hybridize to oligo(dT) and be cleaved by RNase $\mathrm{H}$; and (4) multiple steps are needed that potentially subject the RNA to nonspecific degradation.

Recently, other procedures have been described that improve on the RNase H/oligo(dT) assay. Previously, we reported an assay [PCR Poly(A) test] ${ }^{(2)}$ that allows screening for changes in $\operatorname{poly}(\mathrm{A})$ tail length. This assay is fast and requires little initial material. However, the nature of the assay makes it difficult to accurately estimate poly(A) tail size. A second technique, RNA ligase-mediated rapid amplification of CDNA ends (RLMRACE), was used to determine the length of poly $(\mathrm{A})$ tails in Tetrahymena thermophila. $^{(3)}$ This technique has excellent sensitivity and tail length quantitation; however, it involves multiple steps with intermediate RNA repurifications that can subject the RNA to degradation as well as a cumbersome single-stranded ligation.
To facilitate our analysis of translational control of maternal mRNAs by cytoplasmic polyadenylation, we have developed a new assay that allows us to accurately determine the polyadenylation status of any mRNA in minute samples. In this report we validate the poly(A) test (PAT) utilizing known murine maternal mRNAs and explore some of its potential applications. The PAT has also been used to establish Drosophila as a model system for translational control by polyadenylation. ${ }^{(4)}$

The PAT provides many advantages over previous poly(A) tail analyses: (1) Speed-PAT can be performed in 1 day, including RNA isolation and analysis of PCR products; (2) ease-a sequential one-tube reaction allows generation of a PAT cDNA library that can be used to analyze multiple RNAs; (3) sensitivity-PAT can be used for single-cell analysis; and (4) quantitation-targeting an adapter sequence to the $5^{\prime}$ end of the reverse transcription primer in conjunction with gel analysis of small PCR products allows accurate estimation of poly(A) tail length.

\section{MATERIALS AND METHODS}

\section{PAT CDNA Synthesis}

The acid-phenol method of mRNA purification was used ${ }^{(5)}$ on $20-419$ isolated primary oocytes and pooled aged secondary oocytes ${ }^{(6)}$ with no additional carrier RNA. However, any RNA isolation procedure should be adequate, and we have also used the guanidine isothiocyanate method described in Huarte et al. $^{(1)}$ successfully. An aliquot [equivalent to 20-40 oocytes (8-16 $\mathrm{ng}$ of total $\mathrm{RNA}]^{(7)}$ of RNA in $\mathrm{H}_{2} \mathrm{O}$ was heat-dena- 
tured $\left(65^{\circ} \mathrm{C}\right.$ for $5 \mathrm{~min}$ ) in a $7 \mu \mathrm{l}$ volume in the presence of $20 \mathrm{ng}$ of phosphorylated oligo $(\mathrm{dT})\left[\mathrm{p}(\mathrm{dT})_{12-18}\right]$ and placed directly at $42^{\circ} \mathrm{C}$. Prewarmed mastermix [13 $\mu$ l containing $4 \mu$ l of $5 \times$ Superscript RNase $\mathrm{H}^{-}$reverse transcriptase (RT) buffer (BRL); $2 \mu$ l of 0.1 м DTT; $1 \mu l$ of 10 mM dNTPs; $1 \mu \mathrm{l}$ of $10 \mathrm{~mm} \mathrm{ATP;} 4 \mu \mathrm{l}$ of $\mathrm{H}_{2} \mathrm{O}$; and $1 \mu \mathrm{l}$ of $10 \mathrm{U}$ (Weiss)/ $\mu \mathrm{l} \mathrm{T4}$ DNA ligase (U.S. Biochemical)] was added, and the samples incubated at $42^{\circ} \mathrm{C}$ for 30 $\min$. Subsequently, $1 \mu \mathrm{l}$ of oligo(dT)-anchor (200 ng/ $\mu \mathrm{l}, 5^{\prime}$-GCGAGCTCCGCGGCCGCGT $_{12}$ ) was added at $42^{\circ} \mathrm{C}$ and the reaction transferred to a $12^{\circ} \mathrm{C}$ water bath. After a 2-hr incubation, the samples were transferred back to $42^{\circ} \mathrm{C}, 1 \mu \mathrm{l}(400 \mathrm{U} / \mu \mathrm{l})$ Superscript RNase $\mathrm{H}^{-}$RT was added, and reverse transcription was performed for $1 \mathrm{hr}$. cDNAs were diluted to 1 oocyte/ $\mu \mathrm{l}$ followed by a $30-\mathrm{min}$ incubation at $70^{\circ} \mathrm{C}$ to inactivate the RT and ligase. A schematic representation of PAT cDNA synthesis is shown in Figure 1. An outlined protocol is provided in Table 1.

\section{PCR Amplification}

For PCR amplification, $1 \mu \mathrm{l}$ of PAT CDNAs was added to a standard $50-\mu$ l PCR reaction spiked with $0.5 \mu l$ of $\left[{ }^{32} \mathrm{P}\right] \mathrm{dATP}$ and containing 25 pmoles each of an mRNA-specific primer (see legends) and the oligo(dT)-anchor (amplification conditions: $93^{\circ} \mathrm{C}$ for $5 \mathrm{~min} ; 30$ cycles at $93^{\circ} \mathrm{C}$ for $30 \mathrm{sec} ; 62^{\circ} \mathrm{C}$ for $1 \mathrm{~min}$; $72^{\circ} \mathrm{C}$ for $1 \mathrm{~min}$; with a final extension of $7 \mathrm{~min}$ at $72^{\circ} \mathrm{C}$. After amplification, PCR products were phenol-extracted and ethanol-precipitated with $2.5 \mathrm{M}$ ammonium acetate to remove unincorporated label. Samples were analyzed by autoradiography following electrophoresis on nondenaturing $5 \%$ polyacrylamide gels. Screening for changes in poly(A) tail size can also be performed easily without the addition of radiolabeled nucleotide or the subsequent precipitations by ethidium-bromide staining after agarose gel electrophoresis (see Figs. 3 and 4 , below). To confirm the specificity of the amplification and that the size increase of the PCR fragments was attributable to elongation at the $3^{\prime}$ end of the mRNA, the samples were digested with a restriction endonuclease that cleaves at a known location from the 5 ' end of the amplified region (data not shown, see Ref. 2). This digestion should show a constant $5^{\prime}$ fragment present in all time points and a heterogeneous 3 ' end.

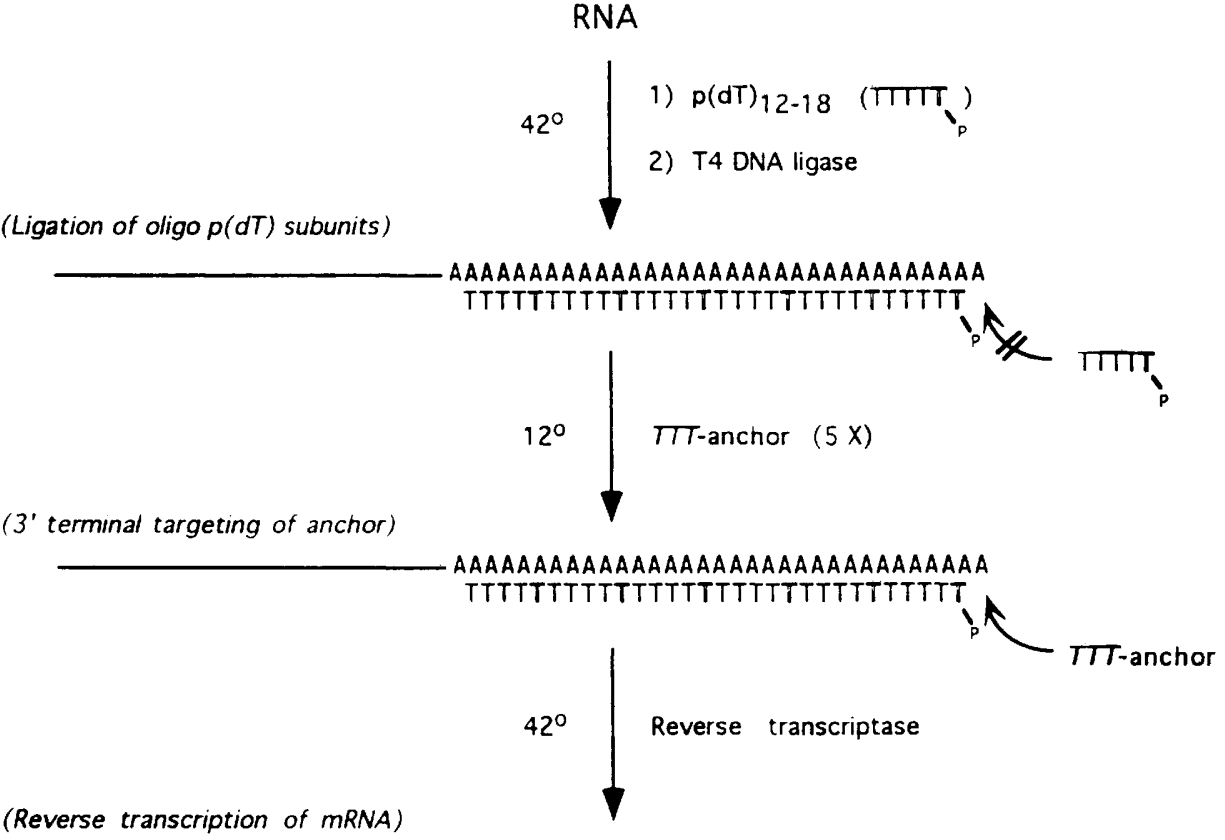

AAAAAAAAAAAAAAAAAAAAAAAAAAAAAAAAAA «- - - - - - TTTTTTTTTTTTTTTTTTTTTTTTTTTTTTTTT-anchor

PCR amplification

mRNA specific prime

TTT-anchor

$\rightarrow$

\section{TITTTTTTTTTTTTTTTTTTTTTTTTTTTTTT-anchor}

FIGURE 1 Schematic representation of the PCR-based PAT. Total RNA is prepared, and phosphorylated oligonucleotide $\mathrm{p}(\mathrm{dT})_{12-18}$ is allowed to saturate the poly(A) tails of the mRNAs. The $\mathrm{p}(\mathrm{dT})_{12-18}$ is then ligated together at $42^{\circ} \mathrm{C}$. This process generates a nearly full-length complementary copy of the poly(A) tail, leaving a short $3^{\prime}$ overhang of oligo(A) as a result of the instability of a short A/dT hybrid at $42^{\circ} \mathrm{C}$. An oligo(dT)-anchor is then added at a fivefold molar excess with respect to $\mathrm{p}(\mathrm{dT})_{12-18}$, and the temperature is lowered to favor the hybridization and ligation of the oligo(dT)-anchor to the extreme $3^{\prime}$ end of the poly(A) tail. After ligation, the temperature is raised and the RNAs are reverse transcribed, using the ligated poly(dT)-anchor stretch as the template primer. The length of the poly(A) tail of a specific mRNA can be estimated by the size of the PCR products after amplifying the cDNA using the oligo(dT)-anchor and a $5^{\prime}$ primer specific for the mRNA of interest.

\section{RESULTS}

\section{PAT Analysis of mRNAs Known to Modulate Poly(A) Tail Length}

The assay was tested by examining the well-characterized dormant, maternal mRNA encoding mouse tissue-type plasminogen activator (t-PA) (Fig. 2). t-PA mRNA contains a poly(A) tail of $\sim 35 \mathrm{nu}$ cleotides in fully grown germinal vesical (GV)-containing oocytes. During oocyte maturation, the poly (A) tail increases to $\sim 365$ nucleotides. Estimates derived by the PAT assay of both the extent and the timing of polyadenylation are similar to those determined previously from Northern analysis. ${ }^{(1)}$
To ensure that the assay was accurately measuring poly(A) tail length, the PAT was applied to actin mRNA, an mRNA known to be deadenylated during the same time course that t-PA is polyadenylated (Fig. 3). ${ }^{(8)}$ Actin mRNA contained a poly(A) tail of $\sim 160$ nucleotides in fully grown GV-containing oocytes and was essentially deadenylated by $6 \mathrm{hr}$ after GV breakdown (GVBD) as determined by the PAT. These values are in agreement with those obtained previously by Northern analysis. ${ }^{(8)}$

\section{PAT Analysis of Differential Polyadenylation}

In Xenopus, maternal mRNAs display dif- 
TABLE 1 PAT Protocol

1. Isolate total RNA.

2. Add $20 \mathrm{ng}$ of oligo $\mathrm{p}(\mathrm{dT})_{12-18}$ to the RNA to a final volume of $7 \mu \mathrm{l}$. Heat-denature at $65^{\circ} \mathrm{C}$ for $5 \mathrm{~min}$. Transfer samples immediately to $42^{\circ} \mathrm{C}$ without an ice-quenching step.

3. Add $13 \mu \mathrm{l}$ of the following mixture (prewarmed to $42^{\circ} \mathrm{C}$ ):

$4 \mu$ l of $5 \times$ Superscript $\mathrm{H}^{-}$RT buffer

$2 \mu \mathrm{l}$ of $0.1 \mathrm{M}$ DTT

$1 \mu \mathrm{l}$ of $10 \mathrm{~mm}$ each dNTP

$1 \mu \mathrm{l}$ of $10 \mathrm{~mm}$ ATP

$4 \mu \mathrm{l}$ of $\mathrm{dH}_{2} \mathrm{O}$

$1 \mu l$ of $10 \mathrm{U} / \mu \mathrm{l}$ T4 DNA ligase

$13 \mu \mathrm{l}$

Incubate for $30 \mathrm{~min}$ at $42^{\circ} \mathrm{C}$.

4. After step 3 , while at $42^{\circ} \mathrm{C}$, add $1 \mu$ l of $200 \mathrm{ng} / \mu \mathrm{l}$ oligo(dT)-anchor.

5. Vortex, microfuge, and incubate at $12^{\circ} \mathrm{C}$ for $2 \mathrm{hr}$.

6. Transfer the samples to $42^{\circ} \mathrm{C}$ for $2 \mathrm{~min}$.

7. Add $1 \mu \mathrm{l}$ of Superscript $\mathrm{H}^{-} \mathrm{RT}$. Incubate at $42^{\circ} \mathrm{C}$ for $1 \mathrm{hr}$.

8. Dilute cDNAs to desired concentration. Heat to $70^{\circ} \mathrm{C}$ for $30 \mathrm{~min}$ to inactivate ligase.

9. PCR

ferences in both the timing and extent of polyadenylation. ${ }^{(9,10)}$ Two novel mouse maternal mRNAs, cloned on the basis of altered polyadenylation (OM1 and OM2), ${ }^{(2)}$ were subjected to the PAT. PAT analysis demonstrates that these mouse mRNAs are polyadenylated to different extents over a similar time course during meiotic maturation (Fig. 4). Both contained a poly(A) tail of $\sim 60$ nucleotides in fully grown GV-stage oocytes. During meiotic maturation, OM1 receives $\sim 170$ adenosine residues, whereas OM2 receives $\sim 590$. As in the case of t-PA and actin, these data are in agreement with those derived from Northern analysis $\left[O M 1^{(2)} ; \mathrm{OM}^{(11)}\right]$. Combined, these results demonstrate that the PAT accurately determines the polyadenylation state of mRNAs.

\section{DISCUSSION}

\section{PAT Theory}

We routinely perform RNA isolations from cells in the absence of carrier even when dealing with minute samples (e.g., 20 oocytes, $8 \mathrm{ng}$ of total RNA). The presence of carrier should not affect the results, although it is possible that carrier excess will compete for oligo(dT) during the initial ligation reaction. The oligo(dT) must be phosphorylated for the ligation reaction. We use $\mathrm{p}(\mathrm{dT})_{12-18}$ because we feel a heterogeneous mixture will yield cleaner results by allowing greater ligation of the variable sized gaps between multiple elongating poly(dT) chains (see below). The amount of $p(d T)_{12-18}$ in the reaction should be in excess, as too little oligo(dT) or too much RNA will prevent complete ligation of oligonucleotide subunits and possibly lead to misrepresentation of the actual poly(A) tail lengths (see below). The amount of ligase used is in excess to ensure significant activity after $30 \mathrm{~min}$ at $42^{\circ} \mathrm{C}$ for ligation of the oligo(dT)-anchor, which is critical, as the anchor is required for proper amplification of the 3 ' terminus and poly(A) tract.

Theoretically, the $p(d T)_{12-18}$ can anneal anywhere on the poly(A) tail. At $42^{\circ} \mathrm{C}$, the subunit annealing should be weak and allow transient melting and sliding along the poly(A) tract. Ligation will occur when two subunits abut each other in the presence of ligase. Ligation will increase the stability of the elongating chain of subunits along the poly(A) tract, limiting further sliding of the nascent poly(dT) tract. ${ }^{1}$ At the termini of the poly(A) tail, a small single-stranded adenosine residue stretch $(\leqslant 10)$ should remain because of the instability of a short $(\mathrm{A}-\mathrm{dT})$ annealed complex at $42^{\circ} \mathrm{C}$. At this point, an excess of unphosphorylated oligo(dT)-anchor (5- to 10-fold with respect to $\left.\mathrm{p}(\mathrm{dT})_{12-18}\right)$ is added to the reaction and the temperature is lowered to $12^{\circ} \mathrm{C}$. The lower temperature allows annealing of the oligo(dT) to the remaining short poly(A) stretch while the anchored primer excess favors the ligation of the oligo(dT)-anchor versus the $\mathrm{p}(\mathrm{dT})_{12-18}$. After allowing sufficient time to ligate the oligo(dT)-anchor, the temperature is raised and reverse transcription is performed using the nascent poly(dT)-anchor as the primer. At the end of the reaction, the ligase and RT are heat-inactivated to prevent further modifications during subsequent manipulations of the PAT cDNAs. For our experiments, samples are diluted to one oocyte or embryo per microliter. One (equivalent to $350-430 \mathrm{pg}$ initial total RNA) ${ }^{(7)}$ to several microliters of sample can then be directly PCR amplified using an mRNAspecific primer and the oligo(dT)-anchor primer.

\section{PCR and Gel Analysis}

Theoretically, the message-specific primer can be directed anywhere along the mRNA. Primer locations close to the 3 'end (within 400 nucleotides) are preferable because they provide the best PCR product size resolution. An internal primer can be used followed by restriction digest to allow visualization of the PCR products representing the $3^{\prime}$ end of the mRNA. ${ }^{(12)}$ We use the primer program contained in the Genetics Computer Group (GCG) software to identify suitable sequences. We recommend primers that range between 20 and 25 nucleotides, $40 \%-60 \% \mathrm{GC}, T_{\mathrm{m}} \sim 60^{\circ} \mathrm{C}$ and that do not have significant complimentarity to the oligo(dT)-anchor. If spurious amplification products are a problem, the annealing temperature in the PCR can be increased slightly $\left(2-5^{\circ} \mathrm{C}\right)$. If modifying the PCR conditions fails to give satisfactory results, a primer at a different location can be tried.

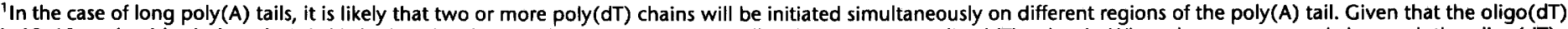

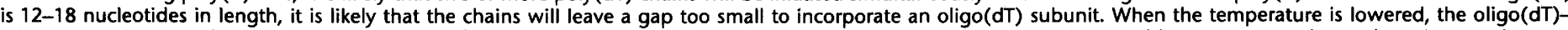

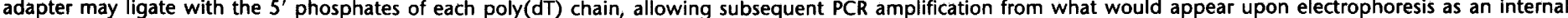

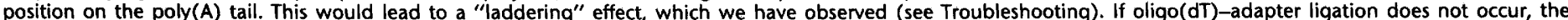
subsequent individual CDNA should not be amplifiable.
} 


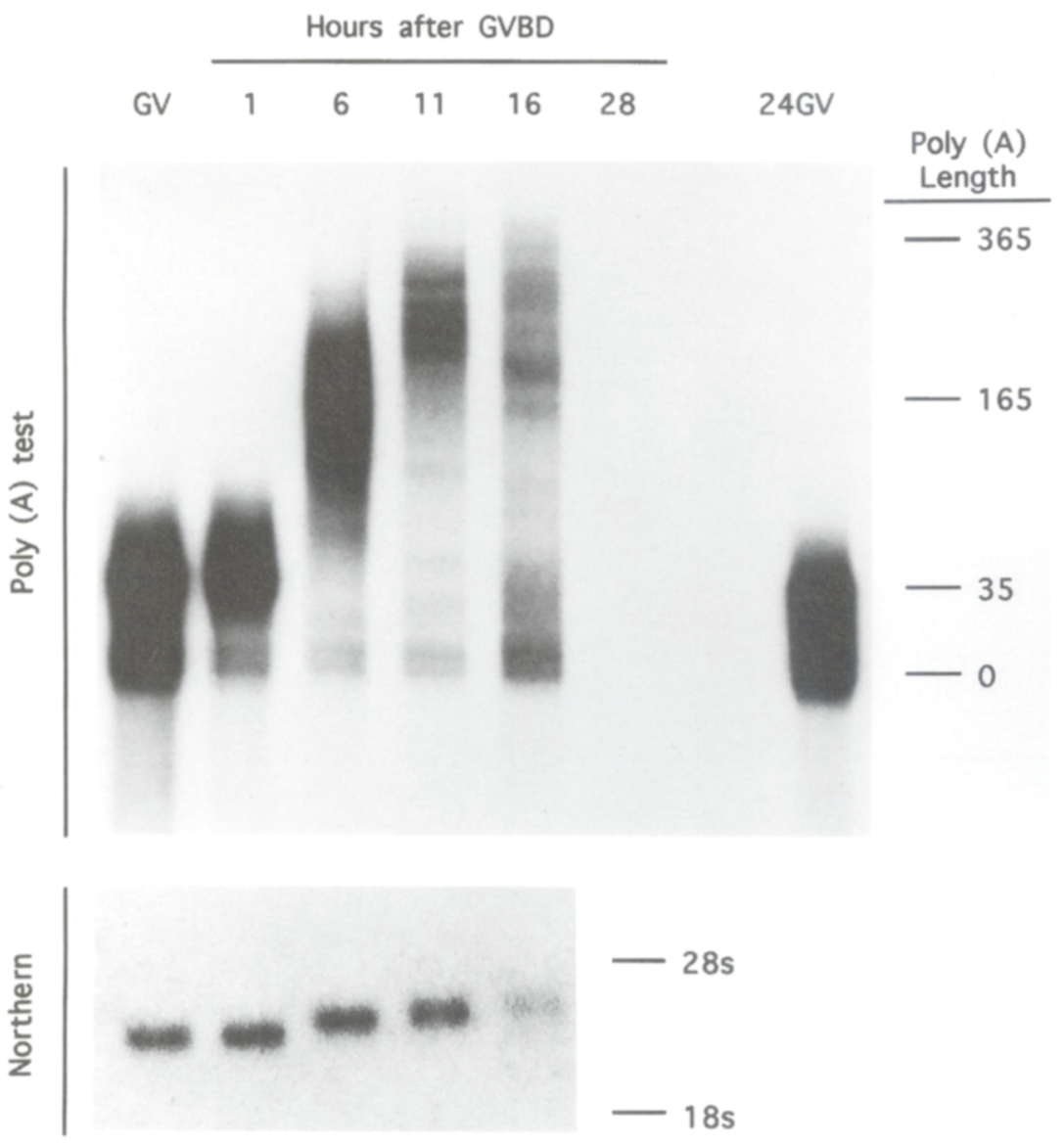

FIGURE 2 The PAT accurately determines poly(A) tail length. PAT was applied to the mRNA for mouse t-PA. (GV) GV-stage oocytes isolated at various times during oocyte maturation [hours in culture after GV breakdown (GVBD)]; (24GV) aged control GV-stage oocytes (prevented from undergoing maturation isolated after $24 \mathrm{hr}$ in culture); these aged GV oocytes do not produce t-PA and do not polyadenylate the mRNA. ${ }^{(1)}$ One oocyte equivalent of PAT cDNAs was amplified per time point. The autoradiograph represents an overnight exposure of $25 \%$ of the PCR products (GV, $1 \mathrm{hr}, 24 \mathrm{hr} \mathrm{GV})$ or $50 \%$ of the products $(6,11,16 \mathrm{hr})$. (t-PA primer) 5 -ACTCTATAGATGGTTGGGAG. The minimum expected size of the amplified products is $185 \mathrm{bp}$ [155-bp t-PA $3^{\prime}$ end $+30 \mathrm{bp}$ of oligo(dT)-anchor]. The estimates of polyadenylation derived from the PAT are in good agreement with those derived from Northern analysis of t-PA mRNA isolated from mouse oocytes over a similar time course (Bottom, taken from Ref. 1). Moreover, the PAT reflects the levels of the mRNA over the time course presented when compared with Northern analysis. Estimates of size are derived from molecular weight standards.

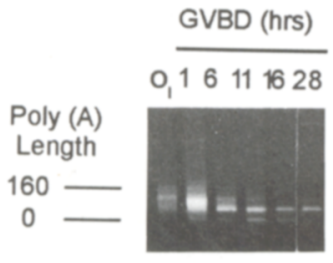

FIGURE 3 PAT accurately determines deadenylation of actin mRNA. PAT PCR products were stained with ethidium bromide after agarose gel ele ztrophoresis. The PAT cDNAs were the sam ones used in Fig. 2, and one oocyte equivalent was PCR amplified with an actin-specific primer (5'-AAGAGGAGGATGGTCGCGTCCATGC). The minimum expected size of the amplified products is $323 \mathrm{bp}$ [293bp actin $3^{\prime}$ end +30 bp of oligo(dT)-anchor]. $\left(\mathrm{O}_{\mathrm{I}}\right) \mathrm{GV}$-stage oocytes. sized fragment, which represents the $5^{\prime}$ portion of the mRNA of interest, in all samples (data not shown; see Ref. 2).

\section{Troubleshooting}

Occasionally, a laddering of PCR products between the expected minimum size and the maximally polyadenylated species is seen and appears to be indicative of unsaturating $\mathrm{p}(\mathrm{dT})_{12-18}$ concentrations or multiple oligo(dT) ligations on individual poly(A) tracts (see footnote above). The intensity and degree of laddering generally varies with each PAT cDNA synthesis. In our experience, additional bands outside of the expected range and/or excessive smearing are generally indicative of $\mathrm{PCR}$ problems. In these instances, the PCR annealing temperature, the number of cycles or, finally, the specific primer selection should be altered to optimize results and not the PAT cDNA synthesis. If problems persist, the RNAs should be DNase treated to ensure that artifacts do not arise from genomic or plasmid DNA contamination. We have successfully used the DNase treatment described in Vassalli et al. ${ }^{(13)}$ with the PAT assay.

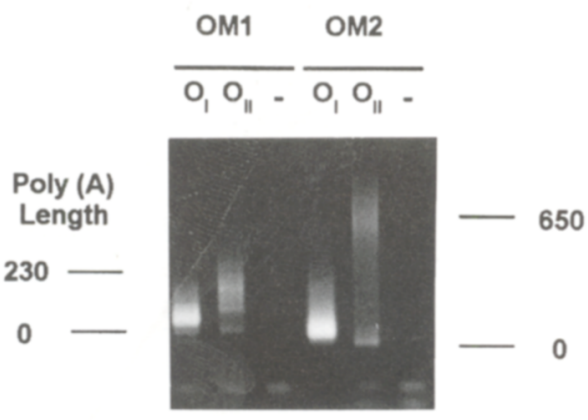

FIGURE 4 PAT analysis of differential polyadenylation. PAT PCR products were stained with ethidium bromide after agarose gel electrophoresis. Shown are two murine maternal mRNAs known to be polyadenylated to different extents during oocyte meiotic maturation. One oocyte equivalent was PCR amplified per sample with a specific primer [(OM1) 5'-ACCAGAAGTGCTAACCGGAATGTGA; (OM2) 5'-CATGTCCAGCTTTTAAGTGG]. The minimum expected size of OM1-amplified products is $124 \mathrm{bp}$ [90 bp of OM1 3 'end +30-bp oligo(dT)-anchor]. The minimum expected size of OM2-amplified products is 89 bp [59-bp OM1 3' end + 30-bp oligo(dT)-anchor]. $\left(\mathrm{O}_{\mathrm{I}}\right) \mathrm{GV}$-stage oocytes; $\left(\mathrm{O}_{\mathrm{II}}\right)$ oocytes that have completed meiotic maturation, $\sim 16-20 \mathrm{hr}$ after GVBD. 


\section{CONCLUSIONS}

The PAT has several advantages for the analysis of polyadenylation. (1) By using the PCR, the sensitivity of the assay is increased such that the analysis can be performed on minute samples (fractions of a single oocyte or embryo). (2) The assay can be performed on total cellular RNA. (3) The ligation and reverse transcription steps can be performed on a larger number of specimens and stored. When a specific mRNA is to be analyzed, a primer for that RNA is synthesized and used in the PCR with the stored CDNAs. (4) The results can typically be visualized with ethidium bromide-stained $2 \%$ agarose gel electrophoresis. For the analysis of rare mRNAs or if a more precise determination of the extent of polyadenylation is desired, the PCR reaction can be carried out in the presence of a radiolabeled nucleotide and separated on polyacrylamide gels. (5) Given all the required reagents, the assay can be done in 1 day.

Given the ease and sensitivity of this assay, it should prove useful for the analysis of any mRNA in any tissue including those already shown to undergo changes in polyadenylation [e.g. vasopres$\sin ^{(14,15)}$ and oxytocin ${ }^{(16)}$ in mice; Cyb, COI, COII, and CR1 mRNAs in Trypanosoma brucei, ${ }^{(17)}$ MST87F in Drosophila $^{(18)}$ ]. Additionally, the assay could be adapted for analyzing sequence or structural requirements that regulate both timing and extent of polyadenylation using microinjected RNAs or with in vitro extracts as well as for the analysis of related topics such as deadenylation of mRNAs.

\section{ACKNOWLEDGMENTS}

We thank Michael Frohman, Marshal Lieberfarb, Christopher Wreden, and members of the Strickland laboratory for helpful discussions in developing the PAT assay. This work was supported by a National Institutes of Health grant (HD25922) to S.S.

\section{REFERENCES}

1. Huarte, J., D. Belin, A. Vassalli, S. Strickland, and J.-D. Vassalli. 1987. Meiotic maturation of mouse oocytes triggers the translation and polyadenylation of dormant tissue-type plasminogen activator mRNA. Genes \& Dev. 1: 1201-1211.

2. Sallés, F.J., A.L. Darrow, M.L. O'Connell, and S. Strickland. 1992. Isolation of novel murine maternal mRNAs regulated by cytoplasmic polyadenylation. Genes \& Dev. 6: 1201-1212.

3. Liu, X. and M.A. Gorovsky. 1993. Mapping the $5^{\prime}$ and $3^{\prime}$ ends of Tetrahymena thermophila mRNAs using RNA ligase mediated amplification of CDNA ends (RLMRACE). Nucleic Acids Res. 21: 4954-4960.

4. Sallés, F.J., M.E. Lieberfarb, C. Wreden, J.P. Gergen, and S. Strickland. 1994. Coordinate initiation of Drosophila development by regulated polyadenylation of maternal mRNAs. Science 266: 19961999.

5. Chomczynski, P. and N. Sacchi. 1987. Single-step method of RNA isolation by acid guanidinium thiocyanate-phenol-chloroform extraction. Anal. Biochem. 162: 156159.

6. Sallés, F.J., W.G. Richards, J. Huarte, J.-D. Vassalli, and S. Strickland. 1993. Microinjecting antisense sequences into oocytes. Methods Enzymol. 225: 351-361.

7. Bachvarova, R., V. De Leon, A. Johnson, G. Kaplan, and B. V. Paynton. 1985. Changes in total RNA, polyadenylated RNA, and actin mRNA during meiotic maturation of mouse oocytes. Dev. Biol. 108: 325-331.

8. Paynton, B.V., R. Rempel, and R. Bachvarova. 1988. Changes in state of adenylation and time course of degradation of maternal mRNAs during oocyte maturation and early embryonic development in the mouse. Dev. Biol. 129: 304-314.

9. Simon, R., J.P. Tassan, and J.D. Richter. 1992. Translational control by poly(A) elongation during Xenopus development: Differential repression and enhancement by a novel cytoplasmic polyadenylation element. Genes \& Dev. 6: 2580-2591.

10. Sheets, M.D., C.A. Fox, T. Hunt, G. Vande Woude, and M. Wickens. 1994. The 3'untranslated regions of c-mos and cyclin mRNAs stimulate translation by regulating cytoplasmic polyadenylation. Genes \& Dev. 8: 926-938.

11. West, M. and S. Strickland (unpubl.).

12. Huarte, J., A. Stutz, M.L. O'Connell, P. Gubler, D. Belin, A.L. Darrow, S. Strickland, and J.-D. Vassalli. 1992. Transient translational Silencing by Reversible mRNA Deadenylation. Cell 69: 1021-1030.

13. Vassalli, J.-D., J. Huarte, D. Belin, P. Gubler, A. Vassalli, M.L. O'Connell, L.A. Parton, R.J. Rickles, and S. Strickland. 1989. Regulated polyadenylation controls mRNA translation during meiotic maturation of mouse oocytes. Genes \& Dev. 3: 2163-2171.

14. Carranzana, E.J., K.B. Pasieka, and J.A. Majzoub. 1988. The vasopressin mRNA poly(A) tract is unusually long and increases during stimulation of vasopressin gene expression in vivo. Mol. Cell Biol. 8: $2267-2274$.
15. Zingg, H.H., D.L. Lefebvre, and G. Almazan. 1988. Regulation of poly(A) tail size of vasopressin mRNA. J. Biol. Chem. 263: 11041-11043.

16. Zingg, H.H. and D.L. Lefebvre. 1989. Oxytocin mRNA: Increase of polyadenylate tail size during pregnancy and lactation. Mol. Cell. Endocrinol. 65: 59-62.

17. Bhat, G.J., A.E. Souza, J.E. Feagin, and K. Stuart. 1992. Transcript-specific developmental regulation of polyadenylation in Trypanosoma brucei mitochondria. Mol. Biochem. Parasitol. 52: 231-240.

18. Schäfer, M., R. Kuhn, F. Bosse, and U. Schäfer. 1990. A conserved element in the leader mediates post-meiotic translation as well as cytoplasmic polyadenylation of a Drosophila spermatocyte mRNA. EMBO J. 9: 4519-4525.

Received January 26, 1995; accepted in revised form March 6, 1995. 


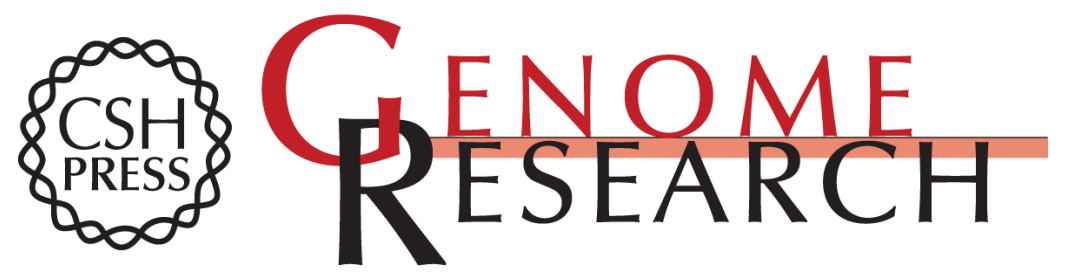

\title{
Rapid and sensitive analysis of mRNA polyadenylation states by PCR.
}

\author{
F J Sallés and S Strickland
}

Genome Res. 1995 4: 317-321 $\begin{array}{ll}\text { References } & \begin{array}{l}\text { This article cites } 17 \text { articles, } 7 \text { of which can be accessed free at: } \\ \text { http://genome.cshlp.org/content/4/6/317.full.html\#ref-list-1 }\end{array}\end{array}$

\section{License}

Email Alerting

Receive free email alerts when new articles cite this article - sign up in the box at the Service top right corner of the article or click here.

\section{Affordable, Accurate Sequencing.}

\section{gencove}

To subscribe to Genome Research go to: https://genome.cshlp.org/subscriptions 